\title{
PT4b Stage Finding
}

National Cancer Institute

\section{Source}

National Cancer Institute. pT 4b Stage Finding. NCI Thesaurus. Code C48774.

A pathologic primary tumor TNM stage finding. The definition of pT $4 \mathrm{~b}$ stage finding depends on the particular type of cancer that it refers to; for example, for breast cancer, pT $4 \mathrm{~b}$ stage finding is defined as follows: cancer with ulceration and/or ipsilateral satellite nodules and/or edema (including peau d'orange) of the skin, which do not meet the criteria for inflammatory carcinoma; for gastric cancer, pT 4b stage finding is defined as follows: cancer with tumor invading adjacent structures. (from AJCC 7th Ed.) 